\title{
Queer or Cripped? An Analysis of Ability in Stone Butch Blues
}

\section{Storm Christine Pilloff \\ Wilmington, North Carolina}

\section{Abstract}

The relationship between the term queer and cripped is deeply reliant on compulsory structures that sanction hetero-normative and able-bodied precedents in society. The similarities between the two terms can be seen in queer narratives (and real lives) exemplified by the character of Jess in Stone Butch Blues. In this essay, I read Feinberg's text through a disability studies/Crip Theory lens to show the extent to which both queer and cripped individuals' identities rely on compulsory structures in society. I cite Robert McRuer in multiple scene analyses. The sexual practices Jess participates in throughout Stone Butch Blues are very similar, if not identical, to the theories and practices Siebers writes about in his essay. For Feinberg, and Jess, the point is to show how people do not need to be fixed for there to be a happily ever after, but in fact, "the primary target for intervention should be social norms and practices rather than individuals."

Key words/tags:

Queer, Crip theory, Cripped, Hetro-normative

Correspondence information:

scp7984@uncw.edu 


\section{Introduction}

The relationship between the term queer and cripped is deeply reliant on compulsory structures that sanction hetero-normative and able-bodied precedents in society. The intersections of which are identifiable in Leslie Feinberg's Stone Butch Blues. Studying Feinberg's text and the various ways sex and identity are addressed and/or represented exposes how queerness is differently-abled, specifically in sexual contexts-but also socially. In this essay I will use the pronouns ze and hir in an effort to faithfully express the gender trouble of Jess who says, "There's never been many women in the world I could identify with. But I sure as hell don't feel like a guy, either. I don't know what I am" (217).

Stone Butch Blues revolves around a natural born female, Jess, who is used to being gawked at for the way ze looks, although ze has no physical (or mental) impairment. Long before ze starts to dress in men's clothing and begins to discover hir queerness, Jess is leered and stared at, constantly asked "Are you a boy or a girl?" throughout hir entire childhood (Feinberg 16). Jess's parents force hir into dresses and charm school in hopes of molding hir into the ideal compulsory hetero-normative female as Adrienne Rich theorizes in 1980; "'I'm sick of people asking me if she's a boy or a girl,' [Jess] overheard [hir] mother complain..." (Feinberg 19).

\section{Queer or Crip? Both And?}

The stare is the beginning of where the correlation between queer and crip (or disabled/differently abled) come in. Both able-bodiedness and heterosexuality are compulsory ${ }^{1}$ categories inextricably tied together. Robert McRuer writes, "To 'claim [critical] disability,' it would seem, is to reject the cultural devaluation of disability and to recognize disability as a vital force that constantly reshapes culture despite ableist norms that would relegate it to a supporting role" (96) . McRuer's claim is that both queer and disabled represent a visible reshaping of culture. This evolves into his Crip Theory: a fusion of disability studies and queer theory. Jess, in this sense, is both queer and cripped; hir identity, as perceived by greater society, is a queering of the body. In other words, because Jess's gender presentation challenges compulsory hetero-normative structures of sex/gender hir appearance is a queering of the socially sanctioned female body. As McRuer articulates it, Jess's physical presentation "reshapes [female sexuality] culture despite ableist norms." In so doing, Jess is not only queer, but it is precisely because ze is queer that ze is also cripped; queer and culturally disabled is cripped. Crip, in this new context, means a queering of the body and its uses; the body functioning and being used in non-compulsory ways. In many ways this blends the meanings of queer and crip, but to clarify, crip refers to a sense of function and less of an identity politics. This is what McRuer addresses when he writes, 
"The verb phrase thus parallels queer, which similarly has been used to describe not just a thing but a process. 'To queer,' I suggest elsewhere, is 'to bring out the difference that is compelled to pass under the sign of the same.' ... queering entails rejecting cultural devaluation and reshaping heterosexist norms, and claiming disability entails bringing out the multiple differences that are compelled to pass under the sign of the same. (96-97)"

In other words, queering rejects heterosexist norms, and when applying that word to disability we get crip or in the above quotation, critical disability, which embraces the philosophy of queer and further applies it to bodily differences and/or activities that also reject the same heterosexist norms. Compulsory ablebodiedness relies on compulsory heterosexuality since the latter depends on certain sanctioned practices that differently-abled bodies aren't qualified for "under the sign of the same."

Thus, Jess's cripness comes in many forms. First, and arguably most importantly, is the way ze looks. Hir physical attributes create a kind of socially cripped lifestyle. In other words, Jess's lifestyle-economically, socially, legally-is predicated on the way ze looks. And, of course, Jess looks queer in that ze doesn't represent the compulsory heterosexually ideal female, or male, even: "Brian says you're a girl, but I think you're a sissy boy," taunts one of Jess's classmates (17). Furthermore, McRuer's statement hinges on "despite ableist norms" which not only refers to people without impairments, but also hetero-normatively able. Literarily Jess serves, in this case, as a character who eventually recognizes queerness, and hir own queerness, as a vital force that constantly reshapes the compulsory culture that continues to try and relegate it to a supporting role.

Because ze is so different, Jess is the object of judgmental stares; hir anxiety about them parallel the old "freak show" in which disabled people would be put on show to entertain an able-bodied audience. It is interesting to note that Jess is coming of age in the 1960's, a meager 20 years after the end of American freak shows. "The Cultural Work of American Freak Shows," as Rosemary Garland Thompson names it, is reflected in the gawking and constant badgering by the public. While Jess is not literally on a stage for the public's entertainment and voyeurism, ze is still very much in the spotlight, and the cultural work of American freak shows created a precedent: (compulsory hetero-normative) able-bodied people stare and "project cultural characteristics" upon anyone not within the realm of those compulsory categories (55).

\section{Jess and Angie}

Nevertheless, Jess begins to understand hir differences. Ze finds bars and jobs in which ze discovers people just like hir. In so doing, Jess begins to understand 
hir identity as a butch and begins to mature into a sexual being. Jess's first (consensual) sexual experience is led by an older pro, Angie, and is Jess's first experience with a strap-on. The entire narrative of the strap-on is within the realm of Tobin Seibers' "A Sexual Culture for Disabled People." Jess and Angie aren't disabled in the general sense of the word, but they are disabled from performing normative sex acts within the realms of compulsory heterosexual society. Because of that, they can be considered cripped in a sexual context as well as the social context aforementioned. In the scene with Angie, Jess remembers what Jacqueline told her about dildos: "You could make a woman feel real good with it or you could make her remember all the ways she's ever been hurt" (71). Jacqueline, in Jess's memory, is referring to the ways in which pros have been hurt by their johns and pimps. In many ways, the harm done to them wounds them, whether physically, mentally, or by driving them to drugs. Jess knows that a dildo can be weaponized against Angie, but it's also worth noting how a dildo can be weaponized against Jess. With that said, the dildo wields a power that can either inflict the same harm compulsory hetero-normative society does, or it can be cripped, or queered, to express love outside of those compulsory dimensions. This is exactly what Carrie Sandahl means when she writes: "Queering describes the practices of putting a spin on mainstream representations to reveal latent queer subtexts; of appropriating a representation for one's own purposes, forcing it to signify differently; or of deconstructing a representation's heterosexism" (49). In this instance, Jess's first encounter with a strap-on, ze is forced to recognize how using this item is embodying a spin on the mainstream representation of such phallic shapes, including the original form, a man's penis. If Jess fails to put a spin on it, ze can "make [Angie] remember all the ways she's ever been hurt" (71). Angie and Jess both are charged with re-appropriating the strap-on for their own queered purposes. In so doing, the strap-on will signify differently than it does in mainstream culture, and it certainly deconstructs its heterosexism because Angie and Jess use it in non-hetero-normative sex acts.

Jess narrates the scene saying, "[Angie] took the rubber cock in both her hands. The way she touched it mesmerized me. 'Feel how I'm touching you,' she whispered with a smile... her mouth was very near my cock" (71). In this instance, Jess first refers to the strap-on with "the" signifying a separation from it. Only after Angie whispers, "Feel how I'm touching you" does Jess adopt the strap-on as hir own, referring to it as, "my cock." In his essay Seibers states, "Disabled people may advance a different sexual geography both for the body and for the places where bodies express their sexuality" (50). In this sense then, Jess and Angie can be read as cripped erotics. Jess advances a different sexual geography for hir own body by becoming one with the strap-on, and both Angie and Jess advance a different sexual geography for where their bodies express sexuality. While, yes, they are in a bedroom, the mainstream location for sex acts, they re-map their bodies' geographies for where they express their sexualities with each other. Although Angie is receiving Jess in the normative way and bodily 
location, Jess is not performing with Angie in hir normative way, nor with hir normative bodily location. In fact, Jess's performance hinges on a prosthetic ze must identify with to fully succeed in hir role with Angie. In so doing, not only is Jess's sexual geography changed, but Angie's is, as well since she is receiving Jess's prosthetic, not the organic phallus heterosexist society constructs sexuality around.

Jess's narration continues; "'If you're going to fuck me with this,' [Angie] said, stroking it, "then I want you to feel it. This is an act of sweet imagination"' (71). To this idea, Seibers writes, "disability [is not] a defect that needs to be overcome to have sex but a complex embodiment that enhances sexual activities and pleasure" (47). Jess's lack of an organic penis is not a defect that Angie, or any femme (or Jess hirself), feels Jess must overcome to have sex. In fact, Jess's organic state allows hir to embody the strap-on because it queers the circumstances of Angie and Jess's experience together and enhances their sexual activities and pleasure. Furthermore, in contemporary popular rhetoric there is a lot of scoffing at this method of lesbian sex; "why not just be with a man if you're going to use a strap-on?" cry the unaware hetero-normative compulsory public, the same public who gawk and judge Jess in Stone Butch Blues. For Angie, it is precisely the queering of normative sex practices on Jess's body that enhances her sexual experience. For Jess, it is the cripping of hir own body, the fact that ze doesn't need to use the spaces on hir body that have been wounded or that represent hir incorrectly, but that ze can use a third party device as an extension of hirself and be empowered by it to please hir partner. Furthermore, Seibers writes, "To reconceive sexuality apart from ability, it would be necessary to imagine the sexual benefit of a given impairment, to claim and celebrate it as a sexual advantage" (43). This is the "sweet imagination" Angie speaks of Jess's lack of an organic penis has allowed for an opportunity for hir and hir partner to "imagine sexual benefit" from that normatively read "lack." It, in fact, presents an opportunity for Angie and Jess to "celebrate it as a sexual advantage," even more specifically since a strap-on can be used violently against Angie, and also because Jess's ability to perform sex in other ways could and would include violence toward hir. In Seibers' context, when he refers to ability it is within the confines of compulsory able-bodiedness. In this sense then, referring to Jess and Angie's sex scene as "sexuality apart from ability" is within the greater conversation in Crip Theory. This assertion is not an attempt to proclaim Jess (or Angie) as disabled individuals, but in fact, very able within the realm of Crip Theory-a space where non-compulsory heterosexual people (therefore, noncompulsory able-bodied people) can find and exploit their non-compulsory bodies for pleasure.

Indeed, for Angie, it is Jess's transformative appearance that arouses her. Abby Wilkerson writes of this appeal to gender inter-determinacy in "Normate Sex and its Discontents" quoting Sonya Bolus's letter to her lover, "I notice that much of my desire is linked to the disparity between your gender expression and your 
body. When you bind your breasts, pack a dick, when you wear a suit and tie, T-shirt and boxers, when you shift before my eyes from woman into man, I am aroused, excited beyond belief" (Bolus as quoted in Wilkerson 202). This is what happens in the scene between Angie and Jess. It begins with Angie noticing Jess's distress. Upon asking Jess to open up about it, "'C'mere baby, sit down.' She pulled up a kitchen chair next to me 'I'm OK,' I said. 'Uh-uh. You're not talking to the butches now'"(70). The combination of Jess's identifiable (stereotypical) female characteristics (i.e., hir emotions) and hir toughness, or butchness, visibly arouses Angie which leads to "'I'm sorry you got no place to go with it. Bring it to me now. It's OK.' [Angie] held me inside her warmth... Then my lips brushed against her breast and a sound escaped her throat...That's when I knew sex is very powerful" (70). As Wilkerson articulates, "it is the inter-determinacy, the shifting range of masculinities and femininities, that provides the erotic charge" (203). It is precisely Jess's cripped nature that excites Angie and leads to their sexual act. What makes Jess disabled in compulsory society enables hir eroticism within hir community. As Wilkerson says, "sex, gender, and sexuality interact with ability and disability in the social constitution of personhood and how gender, ability, and disability are profoundly interwoven in bodily norms" (Wilkerson 184).

\section{Gender fluidity and safety}

On the topic of gender inter-determinacy is Jess's personal gender identity. This is such an enormous problem not only within the text, but when relating Jess to contemporary social issues. However, within the purview of disability studies and Crip Theory, the analysis and deconstruction of Jess's (and other trans identities) comes wrapped in a pretty and simple package. Jess and Grant are discussing the prospect of taking hormones and the idea of being a man trapped in a woman's body. When Grant suggests Jess look into the program for transsexuals, Jess responds, “I don't feel like a man trapped in a woman's body. I just feel trapped"(159). Jess is unable to identify, or articulate, what traps hir. This conversation between Jess and Grant takes place after Jess's longtime girlfriend leaves hir because Jess begins to consider taking male hormones. The thing is, Jess wants to take male hormones so that ze can pass safely, not because ze feels like a man. This scene is set in the 1960's, a historical moment in which violence was committed against people like Jess, oftentimes by the police.

With that said, it can be reasonably deduced that what traps Jess is the society in which ze is victimized by with constant attacks, rude strangers and service workers, and police raping hir. Jess's queer/cripped representation incites hatred, violence, and an overall poor quality of life. Abby Wilkerson's "Normate Sex and its Discontents" is in regards to intersexual, transgender, and transsexual individuals and how they relate to Crip Theory and disability studies. Wilkerson writes, "even if transgender demand for medicalization is not medically created, it is socially imposed, insofar as cultural demands for conformity to the sex/ 
gender binary produce felt needs for one's body to accord with one's gender expression as dictated by hetero-patriarchal convention" (194). Wilkerson's point is the real lived dangers and poor lifestyle Jess must succumb to as a butch lesbian. Jess must, in some way, submit to the compulsory sex/gender binary demanded by society. In so doing, ze enters Wilkerson's discussion of "normate sex" in which she writes, "From this vantage point, intersex and transgender bodies and lives underscore the importance of non-normative sexuality as a constitutive feature of the social category of disability" (184). So because Jess's sexuality is considered non-normative it puts hir into "the social category of disability" meaning that ze is regarded in much of the same way a disabled person is regarded by greater society.

To this Seibers says a few things: "Because a sex life depends on ability, any departure from sexual norms reads as a disability, disease, or defect" (42). Again, ability here refers to ability within compulsory hetero-normative social conventions. The sexual norms he mentions also hinge on compulsory standards which, in Jess's sex life, are visible in the differences based on hir representation, and therefore, read as a disability, disease, or defect. Jess's alternative sexuality is literally thought to be an illness or impairment and in a sick twist of justice, it is precisely because people perceive hir to be disabled, that ze becomes disabled. Society is the only impairment Jess has. Society is the body Jess feels trapped inside. As Wilkerson articulates in the above quotation, society demands conformity. If the world Jess lives in were accepting of hir gender fluidity, I suspect ze would not have resorted to male hormones just because "there's no place to hide" (Feinberg 159).

\section{Jess and Annie}

After Jess finds a place to hide among the safety of testosterone and the way it makes hir look and sound like a gender conforming man, ze meets a nice waitress named Annie. In this passage, Jess seduces Annie without ever disclosing to her that ze is not what Annie thinks ze is. Jess keeps hir strap-on under hir BVD'S and rolls a condom on it in a dark room and Annie is none the wiser (190). Throughout the scene, though, there is a spillage of rhetoric that parallels rhetoric among sex for the disabled. First and foremost, after Jess tells Annie ze will give Annie "anything [she] want[s]," Annie admits that she's "always wanted to come before [she] fucks" (190). Firstly, Annie's statement implies that her idea of fucking isn't just anything that makes her come; oral sex, to Annie, isn't "fucking." This hinges on compulsory hetero-normative sex acts which "require a distinctive mapping of the body into limited erogenous zones" (Seibers 47). These limited erogenous zones must, in "normate sex," be related to reproductive qualities.

After Annie admits this desire to Jess, "She turned her head away in shame" (190).Annie's shame is predicated on a desire that she reads as perverted because it's non-normative. Seibers writes, "the fear of disability also stymies 
intimate romantic relations, even when reproduction is not even an expectation in the relationship" (42). Reproduction is nowhere in the equation between Jess and Annie-not because Jess can't literally impregnate Annie, but because they're only a fling and besides, Annie says to Jess, "I don't think I can have anymore kids" (191). Nonetheless, Annie's desire "to come before [she] fucks" makes her feel ashamed because it fronts her desire to do something outside the socially sanctioned sex acts, and especially outside the socially sanctioned sex acts women should want. Disability, in the above Seibers' quotation, refers to Annie's sexual desires that exist outside the compulsory hetero-normative sex acts able-bodied people should desire. This is why "disability also stymies intimate romantic relations, even when reproduction is not even an expectation in the relationship"-because it fronts the non-reproductive sex acts, or the desire to perform non-reproductive sex acts, which read as perverted. Despite the reality that most people participate in non-reproductive sex acts, social dogma still terrorizes the desires for pleasure outside of hetero-normative sex.

To this, Seibers says, "Social stigma would have little impact on sexual behavior if it were not for the fact that ability represents the supreme measure of human choices, actions, thoughts, and values" (41). Ability (read: compulsory heterosexual able-bodiedness) really makes or breaks an individual by this definition. Annie's insecurity in asking Jess for oral sex reveals her lack of ability, or, in other words, her disability, or, in even different words, her own cripped sexuality. "[T]he fact that ability represents the supreme measure of human choices" emboldens Annie to ask Jess to perform oral sex; it is precisely Annie's fusion of non-normative sexual desire (read: cripped sexuality) and her brief confidence in it, brief enough to ask for it, that truly represents a "supreme measure of human choice." In this way, Annie crips her body for her own desires, and uses her cripped nature to achieve pleasure. The same social stigma that results in her shame after asking Jess for this, has led Annie to "reach her orgasm with an almost relaxed trust" as a result of oral sex-non-normative, nonreproductive sex (Feinberg 191).

Also in this scene, and before Jess performs oral sex for Annie but after she asks for it, Jess narrates, "I began to work my body down her, using my lips and tongue to create new erogenous zones all over her rib cage and stomach" (191). Remarkably, Seibers speaks to this: "sexual desire and erotic sensation are remarkably flexible. For example, people with paralysis, who have lost feeling in traditional erogenous zones, have found ways to eroticize other parts of their body" (47). Certainly Annie is not paralyzed and Jess's creation of new erogenous zones on her torso is not predicated on a debilitating injury. However, it is worth noting how, through Annie's desire for non-normative sex, Jess does in fact create new erogenous zones in order to please this cripped desire. Furthermore, Jess's own cripped body and lifestyle help hir to please Annie in her own newly admitted cripped desire. It takes a crip to know (or please) a crip. 
As the scene continues to unfold, Jess uses hir strap-on to mask having an actual penis; Annie has no clue. After the actual intercourse takes place, Jess removes to the bathroom to place a sock where hir dildo had been. Annie joins hir in the bathroom and, "She put her hand gently between my thighs and squeezed the sock. 'I got a lot of pleasure out of this tonight,' she said. 'It was like magic.... 'All magic is an illusion,' I admitted" (192). Jess's admission to Annie resembles Angie's instructions when Jess lost hir virginity: "This is an act of sweet imagination" (71). Jess's deception reveals a disability truth in Annie's pleasure: "co-thinking sex and disability reveals unacknowledged assumptions about the ability to have sex and how the ideology of ability determines the value of some sexual practices and ideas over others" (Seibers 39). Annie, in this instance, is unaware of how disabled the sex she just had was. Annie will never acknowledge her "assumptions about the ability to have sex" because she will never know Jess used a dildo. The success of Jess's performance illustrates the extent to which the ideology of ability really does determine the value of hetero-normative sex practices over non-hetero-normative. This is especially telling in the wedding scene when Jess sees the hatred Annie has for "That fag" (194). It is revealed that Annie hates "queers" and "faggots" all while remaining totally unaware that she had just experienced "magic" at the hands, or strap-on, of one $(192,195)$. Annie's ideology of ability determines the value of "queer sex" to be perverted and pedophilia while remaining convinced that hetero-normative sexual practices are better (195). This proves Seibers' points again when he writes, "the idea of a sex life is ableist" (39). To Annie, a sex life belongs to hetero-normative people and behaviors which do not include homosexuals.

\section{Cripped Queer Text}

Finally, the overall structure of the novel is, in itself cripped. This is to say that even narratives have a physiology they are compulsorily prescribed to. Firstly, McRuer talks about this in his essay "As Good as it Gets: Queer Theory and Critical Disability" saying, "By representing Melvin's disability or 'ailment' as his character flaw, the scene positions his story firmly in already pervasive cultural discourses of disability" in regards to the 1998 film As Good as it Gets (91). Basically, McRuer's argument is that the character of Melvin exists to show how disabled people can be normalized through hetero-normative romance, exemplified by the "happy ending" in the film. In Stone Butch Blues, the character of Jess is not used to exemplify this; in fact, ze is used to show the opposite: the fact that Jess's main character flaw is that ze tries to normalize hirself, rather than "[declare] to the world that [ze's] not hiding," is hir main character flaw and the arc of the novel. Once Jess begins to embrace hir alternative representation and identification, the novel begins to come to a close. 


\section{Conclusion}

About the close of the novel: McRuer also writes, "Able-bodied status is achieved in direct proportion to his increasing awareness of, and need for, (heterosexual) romance" (92). Rather than giving Jess and the readers a neatly and relieving end to the novel, one in which Jess might have given into Ruth's advances, or one in which Theresa comes back, Feinberg gives hir readers an ending that challenges the normative structure of narratives, especially that of cripped, disabled, or queer characters.

Normative narrative structures reinforce hetero-normative ideologies, such as McRuer's assertion of heterosexual romance. For Feinberg, and Jess, the point is to show how people do not need to be fixed for there to be a happily ever after, but in fact, "the primary target for intervention should be social norms and practices rather than individuals" (Wilkerson 184).

Queer sexuality, because of the spaces it inhabits, the actions it perpetuates, the people who perform it, and the ramifications it has for identity politics in compulsory heterosexual and ableist society, is a cripped sexuality. Stone Butch Blues is an example of people who live exclusively in the margins of society. An able body is also a hetero-normative and heterosexual body. People can be one or the other-but some, are neither, like Jess.

\section{Notes}

1 Adrienne Rich's "Compulsory Heterosexuality and Lesbian Existence" which claims that one's sexuality is not chosen, but rather socially constructed. 


\section{Bibliography}

Clare, Eli. "GAWKING, GAPING, STARING." A Journal of Lesbian and Gay Studies: Desiring Disability: Queer Theory Meets Disability Studies 9.1-2 (2003): 257-61. Print.

"different, adj." OED Online. <http://dictionary.oed.com/>. Oxford University Press. 06 May 2014

Feinberg, Leslie. Stone Butch Blues: A Novel. Ithaca, N.Y.: Firebrand Books, 1993. Print.

Garland-Thompson, Rosemarie. Extraordinary Bodies: Figuring Physical Disability in American Culture and Literature. New York: Columbia UP, 1997. Print.

McRuer, Robert, and Anna Mollow. Introduction. Sex and Disability. Durham: Duke UP, 2012. 1-34. Print

"AS GOOD AS IT GETS: Queer Theory and Critical Disability." A Journal of Lesbian and Gay Studies: Desiring Disability: Queer Theory Meets Disability Studies 9.1-2 (2003): 79-105. Print.

Crip Theory: Cultural Signs of Queerness and Disability. New York: New York UP, 2006. Print.

Mitchell, David T., and Sharon L. Snyder. Narrative Prosthesis: Disability and the Dependencies of Discourse. Ann Arbor: U of Michigan, 2001. Print.

Rich, Adrienne. "Compulsory Heterosexuality and Lesbian Existence." Signs: Journal of Women in Culture and Society 5.4 (1980): 631. Print.

Sandahl, Carrie. "QUEERING THE CRIP OR CRIPPING THE QUEER?: Intersections of Queer and Crip Identities in Solo Autobiographical Performance." A Journal of Lesbian and Gay Studies: Desiring Disability: Queer Theory Meets Disability Studies 9.1-2 (2003): 25-56. Print.

Seibers, Tobin. "A Sexual Culture For Disabled People." 2008. Ed. Anna Mollow. Sex and Disability. Ed. Robert McRuer. Durham: Duke UP, 2012. 37-54. Print.

Wilkerson, Abby L. "Normate Sex and Its Discontents." Sex and Disability. Ed. Robert McRuer and Anna Mollow. Durham: Duke UP, 2012. 183-208. Print. 